Landslides Damage Risk Evaluation Model for Mountain Roads- a Case Study in Taiwan

Min-Yuan Cheng, *Yu-Wei Wu, and Jhao-Bo Hsu

Department of Construction Engineering

National Taiwan University of Science and Technology

Taipei, Taiwan 10672, R.O.C

(*Corresponding author: s8722447@yahoo.com.tw) 


\title{
Landslides Damage Risk Evaluation Model for Mountain Roads- a Case Study in Taiwan
}

\begin{abstract}
Landslides not only cause interruption of road traffic but also cause damage to passing by vehicles and injure people in Taiwan. Due to the budget limitation of government, the overall assessments and maintenance of all road slops cannot be fulfilled. Priority of road for maintenance is a crucial task for road maintenance department to identify. The purposes of this research are to develop an assessment method for the landslide risk and to make strategies to maintain or repair the slopes along mountain roads. To aim both needs to take into account the environmental conditions of the slopes, the engineering measures for stabilizing road slopes, the transportation issues, and the human concerns when dealing with the slopes maintenance along the mountain roads. This study firstly establishes the Landslides Damage Risk Evaluation Model (LDREM) to calculate the risk of slope failure, considering the probability of landslides, temporal probability, spatial impact probability, the value of human life, transportation time increased, and travel cost due to detour etc., and then the loss of life and transportation can be calculated. Secondly, based on the value of risk and the risk evaluation, considering the risk acceptance criteria for loss of life could provide assistance for road maintenance department to determine the priority of mountain roads for maintenance.
\end{abstract}

\section{KEYWORDS}

\section{Slope, Mountain-Roads, Probability of Landslides, Risk Analysis, Damage Evaluation} INTRODUCTION

Road is the major transportation construction for the development of society, economic growth and social security. However, the highlands and mountains that cover some $2 / 3$ of the island in Taiwan continue to be shaped by active orogenic forces, with unstable land surfaces subject to rock falls and collapses. Located in the Circum-Pacific seismic zone, Taiwan is exposed to frequent seismic events that further threaten the stability of mountain slopes. Seasonal heavy rains and typhoons scour loosened rock and carry debris downward, across mountain roads, into valleys. These conditions threaten all man-made structures, including roads, built in such areas. In spite of the importance of maintaining the integrity of the island's upland roadways, limited manpower and financial resources hamper efforts to detect and reinforce unstable slopes of priority threat to roads. Therefore, slope failures along roads not only have the potential to cause fatalities and injuries but also cause serious disruption to traffic in Taiwan.

While numerous studies have proposed models to predict road slope collapse, most have focused on assessing slope failure potential to help facilitate road maintenance decision-making (Liao, 2004;Cheng, 2012). However, there has been little research on economic loss caused by traffic disruption, author have not effectively considered in their research the issue of economic needs and benefits. Consider the problem posed by a damaged slope that links two areas with low population densities. Road managers face high premiums in maintaining slope services that demand high costs and provide low benefits. Deciding which slopes deserve immediate maintenance is justified by current budget constraints represent a complex dilemma for road managers. An effective maintenance strategy, therefore, is an optimization problem that is in order to maximize the total benefit delivered. To achieve this objective, accurate and reliable social cost estimates and expected benefits should be calculated. 
Based on the above, this research offers an analysis model to evaluate the potential for disruption to traffic, the risk assessment technique has been applied in this study to evaluate the risk of economic loss caused by traffic disruption include risk to life. The main purpose of this study is to provide information on the risks associated with slope failures to help prioritize and co-ordinate the slope and road improvement programmers and thus avoid disasters, prevent casualties and minimize property damage. Then construct a travel cost estimation model, using ArcGIS to find the shortest path and TransCAD to analyze traffic assignments. Engineering and addition travel cost are then assessed in the Landslides Damage Risk Evaluation Model (LDREM). LDREM developed in this study includes the determination of frequency of landslide incidents, assessment of the consequences of landslides in terms of fatalities and impact on road traffic and finally calculation of the risk levels in terms of Potential Loss of Life (PLL) and risk of economic loss. The primary purpose of this study was to develop a landslides damage risk evaluation model for maintenance of mountain roads.

\section{METHODS}

\section{Landslides Damage Risk Evaluation Model (LDREM)}

In this research risk evaluation approach are constructed by four parts: hazard identification, failure frequencies, consequence estimation and risk estimation (as Figure 1 shown). The Landslides Damage Risk Evaluation Model (LDREM) is proposed in this research.

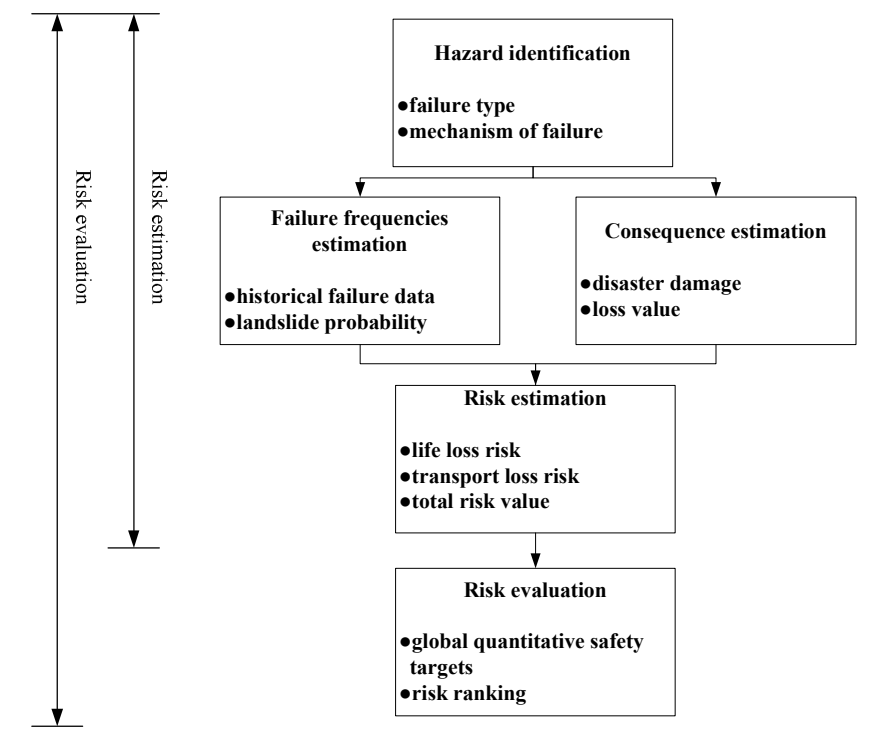

Figure1 Landslides Damage Risk Evaluation Model (LDREM)

\section{Hazard identification}

The objective of first process is to identify all hazards and failure types. Hazard identification is based on a detailed analysis of historical incidents to identify the failure types. The hazards of landslips and their failure modes are considered in detail (ERM-Hong Kong, 1997) which is summarized below. The hazards of landslips can be categorized with respect to type of slope feature and the mechanism of failure. There are 3 types of slope features - cut slope, fill slope, and retaining wall. Cut slopes may be soil cut or rock cut slope. The mechanism of failure for fill slopes may be sliding, washout (failure induced by the scouring action of surface water flow) and liquefaction. Cut slope failures are mainly sliding. The causes of failure are mainly rain infiltration, leaking/ burst water mains, erosion etc. (ERM-Hong Kong, 1997).

\section{$\underline{\text { Failure frequencies estimation }}$}


Failure frequencies may be estimated from historical failure data or from a detailed examination of the causes of failure due to a range of mechanisms (ERM-Hong Kong, 1997). The study collects landslides historical data for slope failures along $21 \mathrm{k}+500 \sim 83 \mathrm{k}+500$ of Provincial Highways Nos. 18 in Taiwan. The total length is $62 \mathrm{~km}$ and 109 incidents during the period 1992 to 2010.

\section{Consequence estimation}

In this research the authors want to discuss the risk that considers two types disaster event caused by passers-by loss when the road slopes collapse. Therefore consequence can be divided into two types: 1.transport losses; 2 . life loss. The parameters of disaster damage and risk values are shown in Figure 2.



Figure 2 Consequence structure

The consequence estimation for landslips involves the estimation of influence distances for different slope heights and the estimation of the probability of fatality for various sizes of failure affecting the many types of facilities at different locations with respect to the influence distance. In order to calculate consequence assessment, the study use statistical analysis to obtain regression model and the relationship between probability, actual Annual Average Daily Traffic (AADT) and the number of lanes. An then estimate travel time delay cost of road slope collapse accidents for different sizes of failure.

\section{$\underline{\text { Risk estimation }}$}

It is common to estimate and express risk in terms of individual risk and societal risk. Individual risk is the risk to specific individuals (for example, various categories of workers, the general public, road users, etc.). Individual risk is in fact a frequency with which individuals within the specified category are expected to suffer the harm. Societal risk is a measure of the overall risk associated with a situation or system. It accounts for the likely impact of all accidental events, not just on a particular type of individual, as in the case of individual risk, but on all individuals who may be exposed to the risk, and it reflects the number of people exposed.

\section{Failure frequencies estimation}

\section{$\underline{\text { Life loss estimation }}$}

Road slope collapse caused casualties with the passers-by; there are possibility of its occurrence, defined as the annual frequency of heavy rainfall, slope collapse probability, the temporal probability and probability of spatial Impact and death probability. The authors draw a process to describe the event. 
The frequency of heavy rain, slope collapse probability, the temporal probability and probability of spatial Impact and the probability of death is the important factors to calculate the loss of life, personal risk, the potential number of deaths each year and the annual value of the social risks. The following procedures are described.

Frequency of heavy rain $\left(\mathrm{F}_{\underline{I}}\right)$, and slope collapse probability $\left(\mathrm{P}_{\underline{L}}\right)$

This study refers Liao's research (Liao, 2005), Provincial Highway No. 18 road slope collapse potential prediction model. The collapse probability is concerned, Gaussian process are used to predict slope collapse potential based on the annual frequency of heavy rain $\left(\mathrm{F}_{\mathrm{I}}\right)$ and impact factors of slope failure $\left(\mathrm{P}_{\mathrm{L}}\right)$ in the reference.

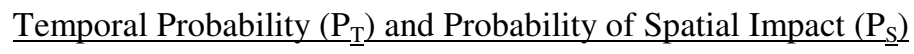

When slope collapse, the impact of vehicles subject to the possibility of earth and rock debris divided into temporal probability and probability of spatial impact (Cheung, 2000). Temporal probability is defined as the possibility of pedestrians, vehicles and people who use structure in the disaster and under disaster affected areas. "Space impact probability" is defined as the possibility of pedestrians, vehicles and people are being affected by disaster. This study applies Poisson distribution to estimate the probability $\left(\mathrm{P}_{\mathrm{T}}\right)$ of rock debris occurs and the vehicle coincides in the same time, as shown in equation 1.

$$
P_{T}=f(x)=\frac{\lambda^{x} e^{-\lambda}}{x !} \quad x=0,1,2, \ldots, \infty
$$

$\lambda:$ The expected number of vehicles within the affected areas when slope collapse.

$x$ : The count of vehicles appear

In equation $1, \lambda$ can be estimated by equation 2 .

$\lambda=\left(Q_{d} / 86400\right) \times T$

$T:$ The required time of vehicles travel freely through the extent of collapse.

$Q_{d}:$ Traffic flow after reduce.

$Q_{d}=A D T \times d_{q}$

$A D T:$ Average daily traffic.

$d_{q}$ : This study refer to ERM (ERM-Hong Kong, 1995), the passers-reduction ratio is 0.8 for wet weather.

When estimate extent of landslide $\left(\mathrm{L}_{\mathrm{e}}\right)$, two conditions need to be considered: 1 . directly affected by debris; 2 . Hit the rock due to brake too slow. Therefore, extent of landslide $\left(\mathrm{L}_{\mathrm{e}}\right)$ should include the possible rock fall length $\left(\mathrm{L}_{\mathrm{f}}\right)$ and the distance of vehicles brakes $(\mathrm{D})$, as calculated by equation 4 .

$L_{e}=L_{f}+D$

$L_{e}$ : Extent of landslide $(\mathrm{m})$

$L_{f}$ : Rock fall length $(\mathrm{m})$

$D:$ The distance of vehicles brakes $(\mathrm{m})$

This study collects landslide historical cases to analyze the relationship between Vf and Lf using regression method (equation 5). Vf could be calculated by using equation 6 (ERM-Hong Kong, 1998).

$$
\begin{aligned}
& L_{f}=1.987995 V_{f}^{0.448852} \\
& V_{f}=30000 A \\
& V_{f}: \text { Earthwork volume }\left(\mathrm{m}^{3}\right) \\
& A: \text { Catchment area }\left(\mathrm{km}^{2}\right)
\end{aligned}
$$

Space impact probability $\left(P_{\mathrm{S}}\right)$ 
This study collects slope failure cases to calculate space impact probability by statistics.

$\beta=\tan ^{-1}\left(H / D_{t}+\left(\frac{H}{\tan (\psi)}\right)\right)$

$H:$ Slope height.

$D_{t}$ : The distance between road and slope toe.

$\psi:$ Slope angle.

In this study, Route T-18 in central Taiwan is chosen to demonstrate the suitability of landslide damage risk evaluation model. According to slope failure historical cases, the probability of influence area between different angles $(\beta)$ is calculated by equation 8 .

$P(\beta)=\frac{n_{\beta}}{N}$

$n_{\beta}:$ the number of slope failure cases when influence shadow angle is $\beta$

$N:$ the total number of slope failure cases

$P_{S}$ can be calculated by sum the $P(\beta)$ from $\beta^{\circ}$ to $90^{\circ}$.

$P_{S}=\sum_{\beta}^{k} P(\beta), k=90^{\circ}$

\section{Probability of death $\left(\mathrm{P}_{\underline{D}}\right)$}

This study applies statistical data from National Fire Agency, Ministry of the Interior, Taiwan to find the information about loss of disaster that includes the total number of casualties or missing. The probability of death (PD) can be estimated by equation 10 .

$$
\begin{aligned}
& P_{D}=\frac{N_{D}}{N_{D}+N_{I}+N_{M}} \\
& N_{D}: \text { the number of death. } \\
& N_{I}: \text { the number of casualties. } \\
& N_{M}: \text { the number of missing. }
\end{aligned}
$$

\section{$\underline{\text { Transport loss estimation }}$}

Due to the collapse of road slope that resulting in the loss of transportation, the study estimated the road slope transport risk of loss according to the incident frequency of the annual heavy rains occur, slope collapse probability, each lane coverage probability. This study assesses the road blocked events into a road partially closed and fully closed type. Summarized the results of annual frequency of heavy rain, slope collapse probability space impact probability and the probability of dying for calculated road slope failures caused the annual transportation necessary parameters. The following will introduce slope failures impact the probability.

\section{$\underline{\text { Slope failures impact the probability }\left(\mathrm{P}_{\mathrm{S}}\right)}$}

The significance of the spatial impact probability represented by the risk assessment of transportation loss is the possibility of road closed after the road collapse and debris avalanche. The probability $\mathrm{P}(\beta)$ calculation equations such as eq.8 and eq.9. $\beta_{1}$ to $\beta_{4}$ were the first to fourth lane center shadow angle. The impact of each lane $\left(\mathrm{P}_{\mathrm{S} \text {,traffic }}\right)$ is taking the impact probability of difference from the center of the lane to the next lane center space.

$$
\begin{aligned}
& P_{S, \text { traffic }}=P_{\beta(i)}^{\prime}-P_{\beta(i+1)}^{\prime} \\
& P_{S, \text { traffic }}: \text { the spatial impact probability of lane i. }
\end{aligned}
$$


$P_{\beta(i)}^{\prime}$ : the spatial impact probability of the center of the lane $\mathrm{i}$ when shadow angle is $\beta \mathrm{i}$

$P_{\beta(i+1)}^{\prime}:$ the spatial impact probability of the center of the lane $i+1$ when shadow angle is $\beta \mathrm{i}+1$

$i:$ the number of lane

In order to achieve the expected travel time delay (TD) when landslide, the weights Di of travel time delay are assigned for various extent of road closed.

$$
\begin{aligned}
& T_{D}=\sum_{i}^{n}\left(P_{S, \text { traffic }} \times D_{i}\right) \\
& \sum P_{S, \text { trafic }}: \text { Spatial impact probability } \\
& D_{i}: \text { Travel time delay } \\
& n: \text { Type of road closure }
\end{aligned}
$$

Di can be calculated by TransCAD. TransCAD is a geographic information system (GIS) designed specifically for transportation professionals to store, display, manage, and analyze transportation data. TransCAD combines GIS and transportation modeling capabilities on a single integrated platform. This research employs TransCAD to perform traffic assignment tasks. Wardrop introduced the UserOptimized Assignment Principle theory into traffic assignment (Wardrop, 1952), and this study follows Wardrop in using Origin-Destination (O-D) matrix and User Equilibrium to measure traffic flows between traffic interdiction and normal traffic without obstruction. User equilibrium assignment is defined as a process by which road users are assigned to networks between two regions in order to achieve minimum travel costs in accordance with the User-Optimized Assignment Principle. Therefore, traffic assignments will be made to achieve minimum travel costs for users. This study employs Beckman's equilibrium assignment (Beckmann, 1956) to analyze equilibrium flow within an equilibrium network. User equilibrium across a transportation network can be stated as an assignment problem and addressed using mathematical algorithms and procedures. As the user utility function is "travel time", the average daily traffic (ADT) value and total travel time delay $\left(\mathrm{D}_{\mathrm{i}}\right)$ of every route can be calculated using a TransCAD traffic assignment function.

\section{Consequence estimation}

The consequence estimation model includes the loss of life risk assessment and transportation risk of loss assessment.

Loss of life risk assessment

Individual risk (IR)

Individual risk can be calculated by equation 13 .

$I R=F_{I} \times P_{L} \times P_{T} \times P_{S, \text { life }} \times P_{D}$

$I R:$ Individual risk (number/year)

$\mathrm{F}_{\mathrm{I}}$ : Frequency of heavy rain (number/year)

$\mathrm{P}_{\mathrm{L}}$ : Probability of landslide

$\mathrm{P}_{\mathrm{T}}$ : Temporal Probability

$\mathrm{P}_{\mathrm{S}, \text { life }}$ : Space impact probability

$\mathrm{P}_{\mathrm{D}}$ : Probability of death

Potential Loss of Life (PLL)

Potential Loss of Life (PLL) every year is calculated by equation 14 .

$P L L=I R \times N_{P}$

PLL : Potential Loss of Life (people/year)

IR : Cost of life (number/year) 
$\mathrm{N}_{\mathrm{P}}$ : Average people in one car (people/vehicle)

Risk of life loss in society $\left(\mathrm{L}_{\mathrm{L}}\right)$

Risk of life loss in society means the total life loss in the road. It can be calculate by equation 15 .

$L_{L}=P L L \times L_{V} \times I_{P}$

$\mathrm{L}_{\mathrm{L}}:$ Risk of life loss in society (dollars/year)

$\mathrm{L}_{\mathrm{V}}:$ Life value (dollars/person)

$\mathrm{I}_{\mathrm{P}}$ : Price index adjustment

The loss of transportation risk of assessment

Loss of traveling $\left(\mathrm{L}_{T}\right)$ closures.

The significance of loss of traveling is travelers' loss time and money due to the landslide road

$L_{T}=F_{I} \times P_{L} \times P_{T} \times T_{D} \times D_{C} \times A D T \times N_{P} \times C_{T} \times I_{P}$

$\mathrm{L}_{\mathrm{T}}$ : Risk of travel loss (dollar/year)

$\mathrm{T}_{\mathrm{D}}$ : Average addition travel time (min. / vehicle)

$\mathrm{D}_{\mathrm{C}}$ : Duration of closure (day)

ADT : Average daily traffic (vehicle /day)

$\mathrm{C}_{\mathrm{T}}$ : Time value (dollar/min)

Loss of operating $\left(\mathrm{L}_{0}\right)$

The approach assumes the vehicle has to travel longer distance at a slower speed due to the likely congestion in other roads.

$L_{O}=F_{I} \times P_{L} \times P_{T} \times T_{D} \times D_{C} \times A D T \times C_{O} \times I_{P}$

$\mathrm{L}_{\mathrm{O}}$ : Risk value of operating cost (dollars/year)

$\mathrm{T}_{\mathrm{D}}$ : Average addition travel time (min. / vehicle)

$\mathrm{D}_{\mathrm{C}}$ : Duration of closure (day)

ADT : Average daily traffic (vehicle /day)

$\mathrm{C}_{\mathrm{O}}$ : Operating cost per minute (dollar/minute)

\section{Risk estimation}

\section{RESULTS}

The purpose of this study is to establish the LDREM for subjective and objective assessment in risk indicators. According the results the order of importance of road slope can be found. To assist management units formulate slope remediation, remediation order and resource allocation strategy, as a basis for risk control. In this study, disaster risk assessment criteria are divided into unacceptable risk, tolerable risk and acceptable risk according to global quantitative safety targets (GQST) (Geotechnical Engineering Office, 1995). (As shown in figure 4)

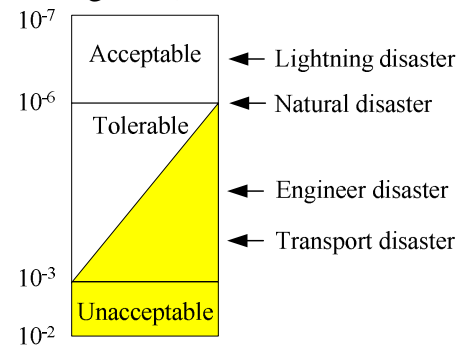

Figure 4 global quantitative safety targets

Estimation of risk to life and economic loss

Otherwise, in this paper consider life los, travel loss and operating cost to estimate the risk of life and economic loss. 
$L_{\text {Total }}=L_{L}+L_{T}+L_{O}$

$L_{\text {Total }}:$ Total risk (dollar/year)

$L_{L}:$ risk of life loss (dollar/year)

$L_{T}:$ risk of travel loss (dollar/year)

$L_{O}$ : risk of operating cost (dollar/year)

The $L_{\text {Total }}$ of 109 route section is calculated as shown in table 1 .

The importance priority of passers life safety is higher than the other aspects loss. Therefore all road slope need divided into three ranks (unaccepted, tolerable and accepted), and then follow this ranks sort those cases by using total risk value criteria $\left(\mathrm{L}_{\text {Total }}\right)$. This road slope important degree of sorting results can be used as the reference of the mountain roads management units on the remediation resource allocation renovation funding, manpower and other resources. First put remediation resources into the "unacceptable risk" level of road slope to prevent dangerous, then the level of "tolerable risk".

Table 1 risk of life and economic loss

\begin{tabular}{|c|c|c|c|c|c|c|c|c|c|}
\hline Type & Rank & route & $\begin{array}{r}\mathrm{L}_{\mathrm{Total}} \\
\text { (NT dollars) } \\
\end{array}$ & Rank & route & $\begin{array}{r}\mathrm{L}_{\text {Total }} \\
\text { (NT do11ars) } \\
\end{array}$ & Rank & route & $\begin{array}{r}\mathrm{L}_{\text {Total }} \\
\text { (NT dollars) }\end{array}$ \\
\hline \multirow{28}{*}{ unacceptable } & 1 & $45 \mathrm{~K}+300$ & $4,423,588$ & 29 & $42 \mathrm{~K}+700$ & $2,594,750$ & 57 & $49 \mathrm{~K}+000$ & $1,592,922$ \\
\hline & 2 & $21 \mathrm{~K}+100$ & $4,398,739$ & 30 & $40 \mathrm{~K}+300$ & $2,588,396$ & 58 & $20 \mathrm{~K}+500$ & $1,566,354$ \\
\hline & 3 & $24 \mathrm{~K}+950$ & $4,144,543$ & 31 & $21 \mathrm{~K}+650$ & $2,501,376$ & 59 & $65 \mathrm{~K}+200$ & $1,561,101$ \\
\hline & 4 & $58 \mathrm{~K}+530$ & $3,810,859$ & 32 & $45 \mathrm{~K}+100$ & $2,488,901$ & 60 & $74 \mathrm{~K}+005$ & $1,541,130$ \\
\hline & 5 & $24 \mathrm{~K}+800$ & $3,730,388$ & 33 & $31 \mathrm{~K}+500$ & $2,453,222$ & 61 & $22 \mathrm{~K}+150$ & $1,462,192$ \\
\hline & 6 & $24 \mathrm{~K}+830$ & $3,671,409$ & 34 & $59 \mathrm{~K}+500$ & $2,374,166$ & 62 & $71 \mathrm{~K}+400$ & $1,428,606$ \\
\hline & 7 & $58 \mathrm{~K}+650$ & $3,667,714$ & 35 & $58 \mathrm{~K}+500$ & $2,370,172$ & 63 & $34 \mathrm{~K}+300$ & $1,399,140$ \\
\hline & 8 & $45 \mathrm{~K}+900$ & $3,646,436$ & 36 & $22 \mathrm{~K}+850$ & $2,358,129$ & 64 & $71 \mathrm{~K}+600$ & $1,349,358$ \\
\hline & 9 & $22 \mathrm{~K}+000$ & $3,513,425$ & 37 & $59 \mathrm{~K}+210$ & $2,266,501$ & 65 & $53 \mathrm{~K}+250$ & $1,326,866$ \\
\hline & 10 & $45 \mathrm{~K}+400$ & $3,389,061$ & 38 & $21 \mathrm{~K}+300$ & $2,266,260$ & 66 & $69 \mathrm{~K}+760$ & $1,299,286$ \\
\hline & 11 & $24 \mathrm{~K}+750$ & $3,250,141$ & 39 & $21 \mathrm{~K}+500$ & $2,259,593$ & 67 & $73 \mathrm{~K}+300$ & $1,255,135$ \\
\hline & 12 & $75 \mathrm{~K}+320$ & $3,225,152$ & 40 & $21 \mathrm{~K}+555$ & $2,138,693$ & 68 & $63 \mathrm{~K}+600$ & $1,234,413$ \\
\hline & 13 & $22 \mathrm{~K}+800$ & $3,196,346$ & 41 & $63 \mathrm{~K}+600$ & $2,038,951$ & 69 & $81 \mathrm{~K}+700$ & $1,176,555$ \\
\hline & 14 & $65 \mathrm{~K}+600$ & $3,101,417$ & 42 & $69 \mathrm{~K}+550$ & $2,036,943$ & 70 & $24 K+700$ & $1,173,166$ \\
\hline & 15 & $26 \mathrm{~K}+600$ & $3,064,653$ & 43 & $28 \mathrm{~K}+250$ & $2,021,304$ & 71 & $51 \mathrm{~K}+000$ & $1,167,685$ \\
\hline & 16 & $66 \mathrm{~K}+340$ & $3,030,347$ & 44 & $69 \mathrm{~K}+700$ & $1,947,630$ & 72 & $61 \mathrm{~K}+500$ & $1,120,893$ \\
\hline & 17 & $26 \mathrm{~K}+700$ & $3,016,751$ & 45 & $43 \mathrm{~K}+200$ & $1,933,133$ & 73 & $79 \mathrm{~K}+650$ & $1,080,803$ \\
\hline & 18 & $66 \mathrm{~K}+100$ & $2,998,897$ & 46 & $53 \mathrm{~K}+850$ & $1,877,414$ & 74 & $61 \mathrm{~K}+250$ & $1,070,381$ \\
\hline & 19 & $26 \mathrm{~K}+700$ & $2,920,365$ & 47 & $26 \mathrm{~K}+100$ & $1,849,241$ & 75 & $70 \mathrm{~K}+300$ & $1,041,479$ \\
\hline & 20 & $57 \mathrm{~K}+010$ & $2,913,849$ & 48 & $42 \mathrm{~K}+500$ & $1,842,837$ & 76 & $73 \mathrm{~K}+700$ & $1,005,743$ \\
\hline & 21 & $66 \mathrm{~K}+040$ & $2,885,538$ & 49 & $21 \mathrm{~K}+850$ & $1,819,686$ & 77 & $26 \mathrm{~K}+300$ & 950,315 \\
\hline & 22 & $22 \mathrm{~K}+300$ & $2,847,445$ & 50 & $31 \mathrm{~K}+700$ & $1,795,521$ & 78 & $60 \mathrm{~K}+900$ & 908,236 \\
\hline & 23 & $77 \mathrm{~K}+900$ & $2,798,877$ & 51 & $28 \mathrm{~K}+300$ & $1,713,492$ & 79 & $75 \mathrm{~K}+000$ & 898,070 \\
\hline & 24 & $22 \mathrm{~K}+900$ & $2,796,150$ & 52 & $78 \mathrm{~K}+950$ & $1,676,850$ & 80 & $21 \mathrm{~K}+400$ & 897,398 \\
\hline & 25 & $65 \mathrm{~K}+700$ & $2,692,119$ & 53 & $54 \mathrm{~K}+150$ & $1,671,829$ & 81 & $47 \mathrm{~K}+300$ & 863,515 \\
\hline & 26 & $58 \mathrm{~K}+000$ & $2,662,319$ & 54 & $56 \mathrm{~K}+700$ & $1,639,482$ & 82 & $67 \mathrm{~K}+400$ & 779,578 \\
\hline & 27 & $25 \mathrm{~K}+550$ & $2,651,538$ & 55 & $38 \mathrm{~K}+450$ & $1,628,048$ & - & - & - \\
\hline & 28 & $22 \mathrm{~K}+400$ & $2,605,294$ & 56 & $35 \mathrm{~K}+100$ & $1,599,936$ & - & - & - \\
\hline \multirow{9}{*}{ tolerable } & 1 & $43 \mathrm{~K}+500$ & $2,146,536$ & 10 & $33 \mathrm{~K}+700$ & $1,207,318$ & 19 & $79 \mathrm{~K}+050$ & 945,632 \\
\hline & 2 & $45 \mathrm{~K}+050$ & $2,125,762$ & 11 & $32 \mathrm{~K}+550$ & $1,170,317$ & 20 & $61 \mathrm{~K}+950$ & 930,329 \\
\hline & 3 & $38 \mathrm{~K}+400$ & $1,921,400$ & 12 & $40 \mathrm{~K}+650$ & $1,155,659$ & 21 & $62 \mathrm{~K}+400$ & 858,681 \\
\hline & 4 & $47 \mathrm{~K}+100$ & $1,554,112$ & 13 & $42 \mathrm{~K}+600$ & $1,155,261$ & 22 & $51 \mathrm{~K}+150$ & 808,383 \\
\hline & 5 & $40 \mathrm{~K}+800$ & $1,479,500$ & 14 & $33 \mathrm{~K}+850$ & $1,153,329$ & 23 & $36 \mathrm{~K}+100$ & 776,800 \\
\hline & 6 & $47 \mathrm{~K}+400$ & $1,474,518$ & 15 & $32 \mathrm{~K}+250$ & $1,100,710$ & 24 & $80 \mathrm{~K}+600$ & 773,796 \\
\hline & 7 & $66 \mathrm{~K}+550$ & $1,449,408$ & 16 & $33 K+300$ & $1,093,928$ & 25 & $59 \mathrm{~K}+950$ & 515,410 \\
\hline & 8 & $30 \mathrm{~K}+750$ & $1,290,490$ & 17 & $52 \mathrm{~K}+850$ & $1,093,691$ & 26 & $59 \mathrm{~K}+750$ & 504,688 \\
\hline & 9 & $76 \mathrm{~K}+000$ & $1,246,882$ & 18 & $53 \mathrm{~K}+050$ & 959,015 & - & - & - \\
\hline
\end{tabular}

\section{CONCLUSIONS}

Evaluating landslide probabilities and risk of slopes along mountain roads is a complicated mater due to large uncertainties. In this paper, a risk analysis model LDREM is proposed to evaluate the risk along a mountain road in Taiwan. The research collect mountain road slope case and use statistics analysis to summarize the relationship between road slope current situation and collapse affect. Furthermore, based on statistical analysis results of the road slope case, to calculate the probability of road slope collapse caused passers-safety hazards and traffic hinder. The result can help mountain road management units to 
find the relationship between road infrastructure, traffic and passers-by damage. The development of LDREM for predicting the life loss and transport loss, when mountain road landslide in the partially closed or fully closed condition. LDREM not only can estimate the risk of different road but also sort the sequence of importance. The Global quantitative safety targets are used to find risk rating, to assist road management unit decision making in remediation of the road slope. Finally, road management units can figure out the slope of the degree of harm to passers-by and slope remediation order in a short period of time by using LDREM.

\section{REFERENCES}

Liao, Lee, Dong, Wu, Wu, (2004). Performance Analysis of Damaged Retaining Structures of Roadway Slopes in Taiwan-Statistic Analysis of Failure Case Studies, Research Projects Science \& Technology Advisors Office Ministry of Transportation and Communications, in Chinese.

Min-Yuan Cheng, Yu-Wei Wu and Kuan-Lin Chen, (2012). Risk Preference based Support Vector Machine Inference Model for Slope Collapse Prediction, Automation in Construction, Automation in Construction, Vol 22, (pp.175-181).

ERM-Hong Kong ,Ltd.,(1997). Slope Failures along Bril Roads : Quantitative Risk Assessment and Ranking, GEO Report No.81, Geotechnical Engineering Office , Hong Kong.

Hung-Jiun Liao, Jian-Ye Ching, Wei-Fon Lee, Jubby Wei, (2005). Landslides along Mountain Roads in Taiwan, The state-of-the-practice of geotechnical engineering in Taiwan and Hong Kong, (pp.7796).

W.M. Cheung \& Y.K. Shiu, (2000). Assessment of Global Landslide Risk Posed By Pre-1978 Man-Made Slope Features : Risk Reduction From 1977 t0 2000 Achieved By The LPM Programme, GEO Report No.125, Geotechnical Engineering Office , Hong Kong.

ERM-Hong Kong ,Ltd, (1995). Feasibility Study For QRA of Boulder Fall Hazard in Hong Kong, GEO Report No.80, Geotechnical Engineering Office, Hong Kong.

ERM-Hong Kong ,Ltd , (1998). Landslides and Boulder Falls From Natural Terrain : Interim Risk Guidelines, GEO Report No.75, Geotechnical Engineering Office.

Wardrop, J. G., (1952). Some theoretical aspects of road traffic research, Proceedings, Institute of Civil Engineers, PART II, Vol.1, (pp.325-378).

Beckmann, M. J., C. B. McGuire, and C. B. Winsten, (1956). Studies in the Economics in Transportation, New Haven, Yale University Press.

Geotechnical Engineering Office, (1995). Landslide Consequence Severity Classification of Roads and Footpaths, ERM-Hong Kong, Ltd. 